\title{
Factor XIII Inactivation
}

National Cancer Institute

\section{Source}

National Cancer Institute. Factor XIII Inactivation. NCI Thesaurus. Code C131670.

Presence of inactivating antibodies to factor XIII in the blood. 